\title{
Customer reliability improvement and power loss reduction in distribution systems using distributed generations
}

\author{
P. Farhadi ${ }^{*}$, H. Shayeghi ${ }^{2}$, T. Sojoudi $^{1}$ and M. Karimi ${ }^{1}$ \\ ${ }^{1}$ Young Researchers club, Parsabad Moghan Branch, Islamic Azad University, Parsabad Moghan, Iran \\ ${ }^{2}$ Technical Engineering Department, University of Mohaghegh Ardabili, Ardabil, Iran \\ pfarhadi@iaupmogan.ac.ir*,tsojoudi@iaupmogan.ac.ir,m.karimi@iaupmogan.ac.ir, hshayeghi@gmail.com
}

\begin{abstract}
Distributed Generations (DGs) because owning many advantages, exist in distribution systems and are installed by either the utilities or the customers. In this paper, a study on reliability of customers and power loss reduction as the two most important aspects of both customers and utilities will be studied. Problem formulation includes several and in contrast to each other individual objectives, hence an optimization algorithm, here dynamic adaptation of particle swarm optimization (DAPSO) was used to allocate multi-DG units in radial distribution systems. To verify the effectiveness of the proposed algorithm in finding best solutions, IEEE 33 bus standard system and a practical system of Tehran (Afsarie)-22 bus are selected as the test systems.
\end{abstract}

Keywords: Customer reliability, Dynamic adaptation of particle swarm optimization, Distributed generation, Power loss, Radial distribution system.

Nomenclature: $k_{m}$ : weighting factors assigned to each objectives. $J_{m}$ : individual objectives. $l_{i}$ : current of ith branch obtained after load flow calculations. $R_{i}$; ith branch resistance, $P_{\text {loss }, i}$ : value of $P_{\text {loss }}$ for ith particle after DG installation. $P_{\text {loss, base: }}$ initial $P_{\text {loss. }} N_{c}$ : elements which their interruptions result in failure. $N_{p}$ : total number of network load points. $\lambda_{i j}$ : failure rate of $j$ th costumer in ith element. $r_{i j}$ : average repair time. $L_{i}$ : average loads of $i$ th load point. EENS: expected energy not supplied for ith particle after DG installation. $E E N S_{\text {base: }}$ expected energy not supplied before DG installation.

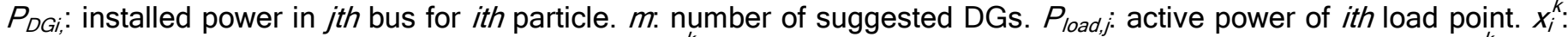
Current position of particle $i$ in $k t h$ iteration, XPbest ${ }_{i}^{k}$ : Best individual position of particle i in kth iteration, XGbest $t^{k}$ : Best global position of particles in $k$ th iteration, $v_{i}^{k}$ : Current velocityof particle $\mathrm{i}$ in $k$ th iteration .iter ${ }_{\max }$ : Maximum number of iterations, iter. Number of current iteration, $c_{1}, c_{2}$ : Acceleration coefficients, $r_{1}, r_{2}$ : Random values with normal distribution in the range of $[0,1], \omega$ : Inertia coefficient, $\omega_{i}^{k}$ : Dynamic inertia coefficient, $\alpha, \beta$ : Values in the range of $[0,1]$, $h_{i}^{k}$ : Evolution speed factor, $s$ : Aggregation degree factor.

\section{Introduction}

In recent years, DG penetration into distribution systems has been increased in the world. For this, the major reasons can be the liberalization of electricity markets, limitations on building new transmission and distribution lines, and environmental concerns (Singh \& Misra, 2007; Ackermann et al., 2001). Technological advances in small and effective generators, power electronics, and energy saving devices for transient backup have also accelerated the integration of DG into electric power distribution networks (Marwali et al., 2007; Seyed Ali Mohammad Javadian \& Maryam Massaeli, 2011a,b,c; Navid Khalesi \& Seyed Ali Mohammad Javadian, 2011).

It is clear that any loss reduction is lucrative to distribution utilities. Loss reduction is therefore the most important factor to be considered in planning and operation of DG (Singh \& Verma, 2009; Ochoa et al., 2008). For instance, multi-objective index for performance calculation of distribution systems for single-DG size and location planning has been proposed (Singh \& Verma, 2009). For this analysis the active and reactive power losses receive significant weights of 0.40 and 0.20 , respectively. The current capacity receives a weight of 0.25 , leaving the behavior of voltage profile at 0.15 . Also, providing high reliability for the customers is of great importance. In a radial distribution feeder, depending on the technology, DG units can deliver a portion of total real and/or reactive power to loads so that the feeder current reduces from the source to the location of DG units. However, it has been indicated that if DG units are inappropriately allocated and sized, the reverse power flow from larger DG units can lead to higher system losses (Acharya et al., 2006; Atwa et al., 2010). Hence, to minimize losses, it is of great importance to find the best location and size of the DG units.

Optimization techniques are extensively utilized for the best sizing and sitting of DG units. There are many approaches for deciding the optimum size and location of DG units in distribution systems. The optimum locations of DG were determined in the distribution network (Thong et al., 2007; Gandomkar et al., 2005; Keane \& O'Malley, 2006). In some research, the optimum location and size of a single DG unit is determined, while in others the optimum locations and sizes of multiple DG units are determined (AlHajri et al., 2007; El-Khattam et al., 2009). A particle swarm optimization (PSO) algorithm was introduced to determine the optimum size and location of a single DG unit for minimizing the real power losses of the system. PSO was used to place multiple DG units
Research article

CIndian Society for Education and Environment (iSee)
"Improvement in DG \& customer reliability" http://www.indjst.org
Farhadi et al. Indian J.Sci.Technol. 
with non-unity power factor, but the objective was to minimize only the real power loss of the system (AlHajri et al., 2007).

In this paper for optimum sizing and sitting of multiDG units for reliability of customers' improvement and power loss reduction, an improved branch of PSO will be utilized and obtained results will be compared with the other techniques which were used for these goals.

\section{Problem formulation}

The main goal of the proposed algorithm is to determine the best locations and sizes for DG units by minimizing different functions related to paper aims. In this work, we are following three goals. The goals are loss reduction, reliability improvement and achieving the formers with reduced DG size. These items should be composed with constraints to obtain the proper objective functions. The overall objective function composing constraints and goals, is determined as

$$
\begin{aligned}
& \text { Minimize } \quad \mathrm{J}=\sum_{\mathrm{m}=1}^{3} \mathrm{k}_{\mathrm{m}} \cdot \mathrm{J}_{\mathrm{m}} \\
& \mathrm{k}_{\mathrm{m}} \in[0,1], \quad \sum_{\mathrm{m}=1}^{3} \mathrm{k}_{\mathrm{m}}=1
\end{aligned}
$$

Where, $k_{m}$ are weighting factors assigned to each objectives, in this paper, are $K_{1}=0.40, K_{2}=0.35, K_{3}=0.25$ attributed to power loss, reliability and DG size, respectively.

\section{First term: power loss}

Power loss has been one of the most important objectives in many researches. Here, power loss will be just one of the individual objectives given by

$$
\begin{aligned}
& \mathrm{P}_{\mathrm{Lt}}=\sum_{\mathrm{i}=1}^{\mathrm{n}} \mathrm{I}_{\mathrm{i}}^{2} \mathrm{R}_{\mathrm{i}} \\
& \mathrm{J}_{1}=\frac{\mathrm{P}_{\text {loss }, \mathrm{i}}}{\mathrm{P}_{\text {loss,base }}}
\end{aligned}
$$

\section{Second term: reliability of costumers}

Reliability of customers is included in objective function as Expected Energy Not Supplied (EENS) by

$$
\begin{aligned}
& \text { EENS }=\sum_{\mathrm{i}=1}^{\mathrm{N}_{\mathrm{p}}} \text { EENS }_{\mathrm{i}}=\sum_{\mathrm{i}=1}^{\mathrm{N}_{\mathrm{p}}} \mathrm{L}_{\mathrm{i}} \sum_{\mathrm{j}=1}^{\mathrm{N}_{\mathrm{c}}} \mathrm{r}_{\mathrm{ij}} \lambda_{\mathrm{ij}} \\
& \mathrm{J}_{2}=\frac{\text { EENS }_{\mathrm{i}}}{\text { EENS }_{\text {base }}}
\end{aligned}
$$

Third term: DG installation cost

To allocate minimum DGs on optimization, DG size (or cost) is considered as the another objective as

$$
\mathrm{J}_{3}=\frac{\sum_{\mathrm{j}=1}^{\mathrm{m}} \mathrm{P}_{\text {DGi }, \mathrm{j}}}{\sum_{\mathrm{j}=1}^{\mathrm{N}_{\mathrm{p}}} \mathrm{P}_{\text {load }, \mathrm{j}}}
$$

Vol. 5 No. 3 (Mar 2012)

ISSN: $0974-6846$
Problem constraints

A) Power balance

$\mathrm{P}_{\text {Slack }}+\sum_{\mathrm{i}=1}^{\mathrm{N}} \mathrm{P}_{\mathrm{DGi}}=\sum_{\mathrm{i}=1}^{\mathrm{N}} \mathrm{P}_{\mathrm{Di}}+\mathrm{P}_{\mathrm{L}}$

B) Active and Reactive Power Limitations of DG

$\mathrm{Q}_{\mathrm{DGi}}^{\min } \leq \mathrm{Q}_{\mathrm{DGi}} \leq \mathrm{Q}_{\mathrm{DGi}}^{\max }$

$\mathrm{P}_{\mathrm{DGi}}^{\min } \leq \mathrm{P}_{\mathrm{DGi}} \leq \mathrm{P}_{\mathrm{DGi}}^{\max }$

C) Power Loss Limitations

$\sum \operatorname{Loss}_{\mathrm{k}}($ withDG $) \leq \sum \operatorname{Loss}_{\mathrm{k}}($ withoutDG)

D) Bus Voltage Limitations

$\left|\mathrm{V}_{\mathrm{i}}\right|^{\min } \leq\left|\mathrm{V}_{\mathrm{i}}\right| \leq\left|\mathrm{V}_{\mathrm{i}}\right|^{\max }$

\section{E) Bus Current Limitations \\ $\left|\mathrm{I}_{\mathrm{i}}\right| \leq\left|\mathrm{I}_{\mathrm{i}}\right|^{\max }$}

Fig.1 shows the flowchart of solving problem of DG allocation.

Fig. 1. Implemented methodology for DG allocation

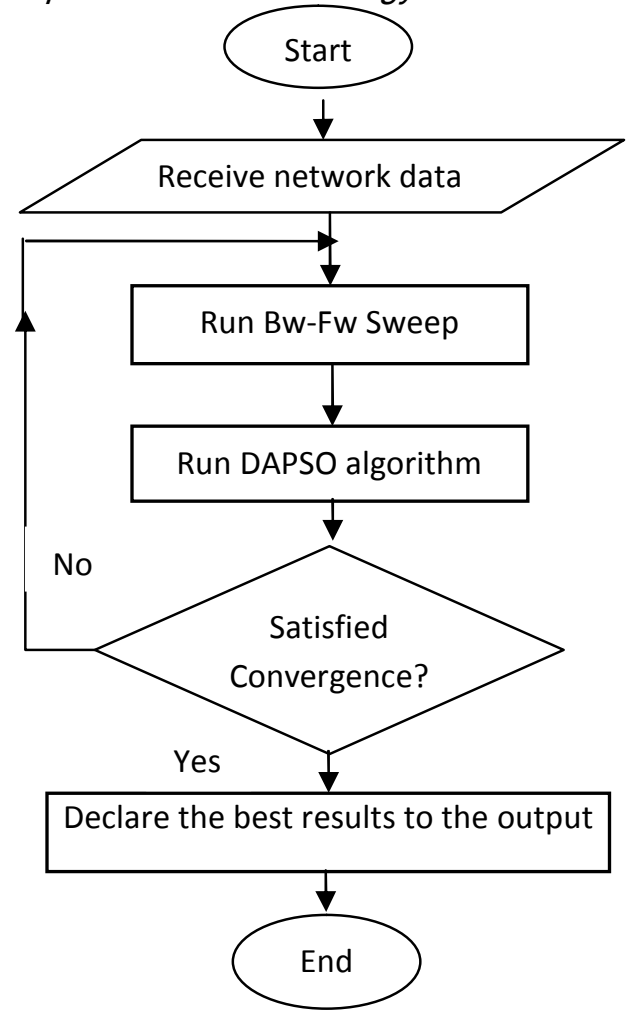

Optimization algorithm Standard PSO

PSO is a population-based intelligent searching algorithm. It has excellent performance in searching for the global optimum. PSO resembles the social behavior of birds or fish when they find food together in a field. 
The performance of this evolutionary algorithm is based on the intelligent movement of each particle and collaboration of the swarm. In the first improved standard version of PSO, each particle starts from a random location and searches the space with its own best knowledge and the swarm's best experience. The search rule can be expressed by simple equations with respect to the position vector $X_{i}=\left[x_{i 1}, \ldots, x_{i n}\right]$ and the velocity vector $V i=\left[V_{i 1}, \ldots, v_{i n}\right]$ in the $n$-dimensional search space as

$$
\begin{aligned}
& v_{i}^{k+1}=\omega v_{i}^{k}+c_{1} r_{1}\left(\text { XPbest }_{i}^{k}-X_{i}^{k}\right)+ \\
& +c_{2} r_{2}\left(\text { XGbest }^{k}-X_{i}^{k}\right) \\
& x_{i}^{k+1}=x_{i}^{k}+v_{i}^{k+1}, \mathrm{i}=1,2 \ldots, \mathrm{n} \\
& \omega=\omega_{\max }-\frac{\omega_{\max }-\omega_{\min }}{\text { iter }_{\text {max }}} \times \text { iter }
\end{aligned}
$$

Here, $\omega \geq 0$ defined as inertia weight factor. Empirical studies of PSO with inertia weight have shown that a relatively large $\omega$ have more global search ability while a relatively small $\omega$ results in a faster convergence; $c_{1}$ and $c_{2}$ set to 2.0; $r_{1}$ and $r_{2}$ as random numbers in $[0,1]$; and $X P b e s t_{i}^{k}$ and $X$ Gbest $t^{k}$ which are the best positions that particle $i$ has achieved so far based on its own experience and the swarm's best experience, respectively.

\section{Dynamic adaptation of PSO (DAPSO)}

By analyzing (10) and (11), it can be seen that, each particles follow two "best" values, the current global best value and the best solution it has achieved so far. The velocity of particles rapidly approach zero, which causes the particles to be stuck in local optima. This phenomenon is called "similarity" of particle swarm, which can be observed through experiments. The "similarity" constricts the search area of particles. Enlarging the search area necessitates either increasing the number of particles or weakening the ability of particles to track the present global best value (Robinson et al., 2004; Chung et al.,2009 ). However, the former entails an enhanced computational complexity and the latter lead to a slow convergence. The velocity and position updating rule is given by

$$
\begin{aligned}
& v_{i}^{k+1}=\omega_{i}^{k} v_{i}^{k}+c_{1} r_{1}\left(\text { XPbest } k_{i}^{k}-X_{i}^{k}\right)+ \\
& +c_{2} r_{2}\left(\text { XGbest }-X_{i}^{k}\right) \\
& x_{i}^{k+1}=x_{i}^{k}+v_{i}^{k+1}, \mathrm{i}=1,2 \ldots, \mathrm{n}
\end{aligned}
$$

Compared with that in the conventional PSO, the velocity updating formula (10) has two different characteristics: the value of $r_{1}$ and $r_{2}$ only vary stochastically with the number of particles and iterations. In other words, in $(k+1)$ th iteration each dimension of the ith particle shares the same random value, the inertia weight is also variable with the number of particles and iterations.

In the algorithm of this paper, the inertia weight is affected by the evolving state of algorithm and determined by the evolution speed factor of each particles and the aggregation degree factor of the swarm given by (15) and (16), respectively;

$$
\mathrm{h}_{\mathrm{i}}^{\mathrm{k}}=\left|\frac{\min \left(\mathrm{F}\left(\text { pbest }_{\mathrm{i}}^{\mathrm{k}-1}\right), \mathrm{F}\left(\text { pbest }_{\mathrm{i}}^{\mathrm{k}}\right)\right)}{\max \left(\mathrm{F}\left(\text { pbest }_{\mathrm{i}}^{\mathrm{k}-1}\right), \mathrm{F}\left(\text { pbest }_{\mathrm{i}}^{\mathrm{k}}\right)\right)}\right|
$$

Where, $F\left(p b e s t_{i}^{k}\right)$ is the fitness value of $p b e s t_{i}^{k}$. Under the assumption and definition above, it can be obtained that $0<h \leq 1$. This parameter takes the run history of each particle into account, and reflects the evolutionary speed of each particle, that is, the smaller the value of $h$, the faster the speed.

$$
\mathrm{s}=\left|\frac{\min \left(\mathrm{F}_{\text {kpbest }}, \overline{\mathrm{F}}\right)}{\max \left(\mathrm{F}_{\text {kpbest }}, \overline{\mathrm{F}}\right)}\right|
$$

Where, $\bar{F}$ is the mean fitness of all particles in the swarm at the kth iteration. Note that $F\left(g b e s t_{k}\right)$ cannot be substituted for $F_{k p b e s t}$, since $F_{k p b e s t}$ represents the optimal value found in this iteration, while $F\left(\right.$ gbest $\left._{k}\right)$ denotes the optimal value that the whole swarm has found up to the $k$ th iteration. The evolution speed factor and aggregation degree factor of the swarm are the two typical characteristic parameters in the search course of DAPSO. The value of inertia weight should vary with the evolution speed and aggregation degree of the swarm. So, $\omega$ can be written as the function of the parameters $h$ and $s$,

$$
\omega_{\mathrm{i}}^{\mathrm{k}}=\mathrm{f}\left(\mathrm{h}_{\mathrm{i}}^{\mathrm{k}}, \mathrm{s}\right)
$$

It is a core problem that how $x$ varies with the evolution speed factor and aggregation degree factor of the swarm. The purpose of the variation is to give the algorithm a better ability to rapidly search and move out of the local optima.

In a search course of an individual (e.g., a particle), if the possibility of finding the object increases (i.e., the convergence rate is relative large), the individual does not rush at the next position with acceleration, but rather decelerates (i.e., decrease the inertia weight) to fly towards the optimal value, which lead to increasing the search intensity in the current small search area. Otherwise, increase the search velocity and the search intensity in a large area. Meanwhile, in order to prevent the similarity of swarm, the ability to jump out of local optima should be enhanced, that is, when the aggregation degree factor becomes larger, the inertia weight should increase proportionally. The inertia weight is given by

$$
\omega_{\mathrm{i}}^{\mathrm{k}}=\omega_{\text {ini }}-\alpha\left(1-\mathrm{h}_{\mathrm{i}}^{\mathrm{k}}\right)+\beta \mathrm{s}
$$

Where, $\omega_{i n i}=1, \alpha$ and $\beta$ is typically within the range $[0,1]$, and here according to many experiments these values are selected $\alpha=0.4$ and $\beta=0.8$.

To calculate the power loss, common backward forward (Bw-Fw) power flow is utilized (Jen-Hao Teng, 2003), Also, for the customers' reliability, EENS is calculated. So to do this, just a breaker is used after source for both test systems and there is no other 
Fig.2. DAPSO algorithm

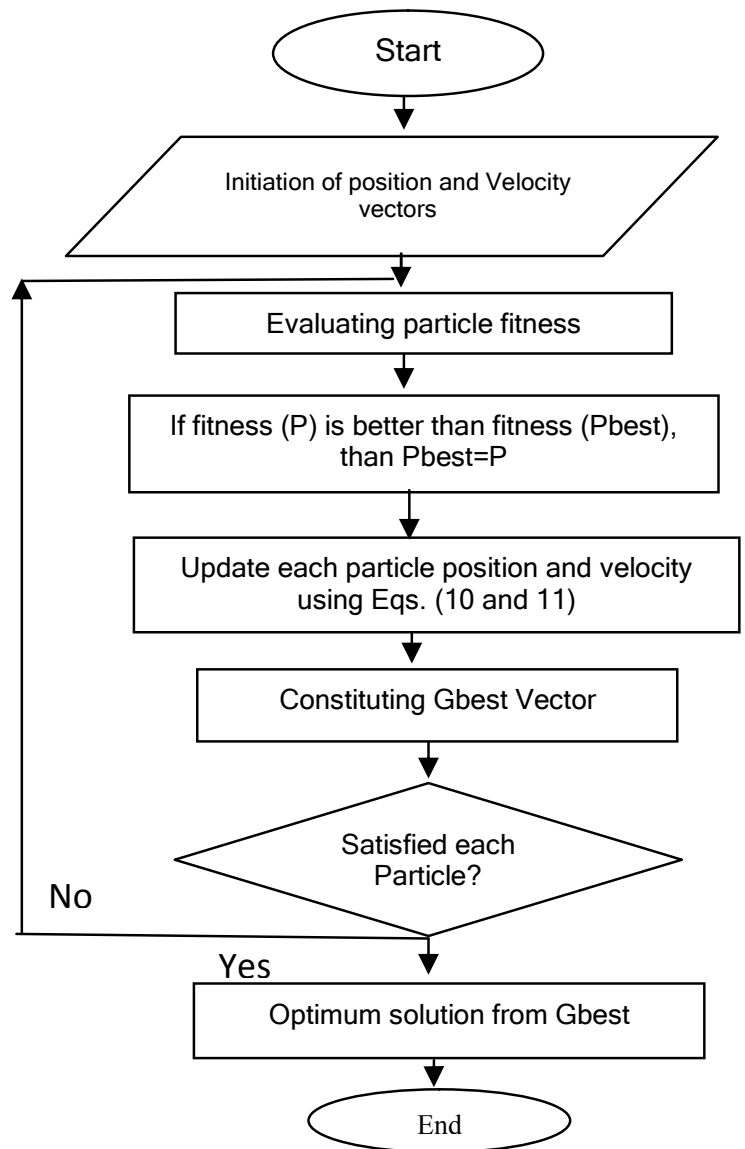

protection device such as fuses, reclosers and etc. Fig. 2 shows DAPSO algorithm.

Numerical Results

In this paper, four DG types; 500, 750, 1000 and $1500 \mathrm{~kW}$ was the available size of DGs in this paper. The proposed methodology is tested on two standard and practical radial distribution systems. The first system used in this paper is IEEE 33 bus radial distribution system. The other is Tehran (Afsarie)-22 bus system.

Fig. 3 IEEE 33 bus test system

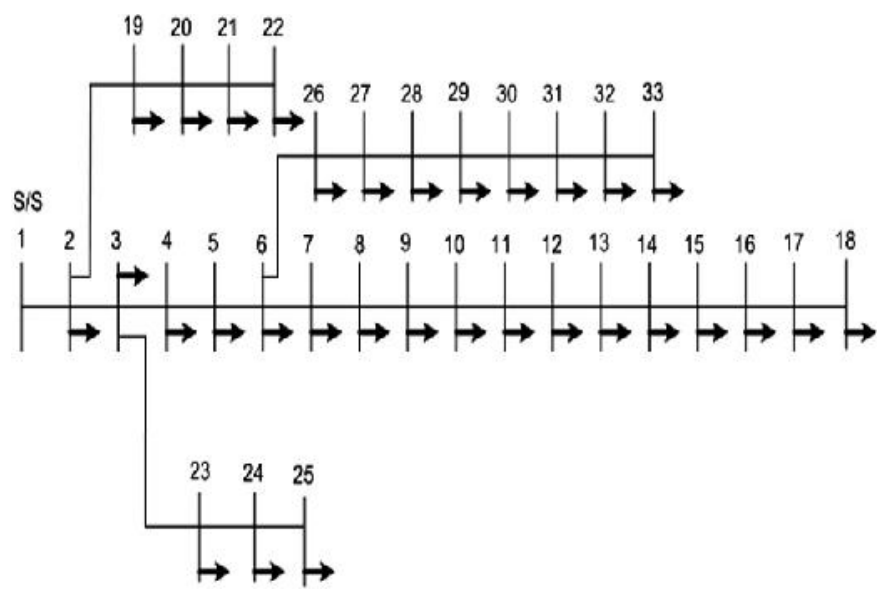

Vol. 5 No. 3 (Mar 2012)

ISSN: 0974- 6846

First Case: IEEE 33 bus radial distribution system

This test system is depicted in Fig. 3 (Kashem et al., 2000).

Table1. DG Placement by various techniques for 33-bus system.

\begin{tabular}{|c|c|c|c|c|c|}
\hline \multirow{3}{*}{ Technique } & \multicolumn{2}{|c|}{ DG Installation } & \multirow{3}{*}{$\begin{array}{l}\text { Ploss } \\
(\mathrm{kW})\end{array}$} & \multirow{2}{*}{\multicolumn{2}{|c|}{ Bus Voltage (p.u.) }} \\
\hline & \multirow{2}{*}{ @ bus } & \multirow{2}{*}{$\begin{array}{l}\text { Size } \\
\text { (MW) }\end{array}$} & & & \\
\hline & & & & Min. & Mean \\
\hline No DG & - & - & 211.20 & 0.9037 & 0.9430 \\
\hline $\begin{array}{l}\mathrm{ABC} \\
\text { algorithm }\end{array}$ & 6,15 & 2.5 & 89.96 & 0.951 & 0.9696 \\
\hline PSO & $8,15,32$ & 2 & 88.99 & 0.9534 & 0.9717 \\
\hline LSF & $18,25,33$ & 2.43 & 85.07 & - & - \\
\hline IA & $6,12,31$ & 2.52 & 81.05 & - & - \\
\hline DAPSO & $\begin{array}{l}7, \quad 10,16, \\
21,27\end{array}$ & 2.5 & 79.18 & 0.9770 & 0.9880 \\
\hline
\end{tabular}

Table 1 presents the results of the optimal sizes and locations of DG units by various techniques (Hung et al, Lathia et al and Falaghi et al., 2004). For multiple DG units, DAPSO achieves a loss reduction of $63.00 \%$, compared with the best of the other techniques i.e., Improved Analytical method (IA) at $61.50 \%$.

In general, for this system, DAPSO method can leads to an optimum or near optimum solution for multiple DG units. It should be noted that for comparison on power loss, although DG sizes are slightly different for the used techniques and this could be neglected.

For reliability evaluation, simulation results show that the EENS values, as an index of reliability, were 14532, 10689 and 9038 in $k W h / y r$ for no DG, PSO method and DAPSO method, respectively. It can be inferred that DAPSO method could increase about $15.5 \%$ and $38 \%$ the reliability of the costumers supply in comparison to the no DG and PSO method.

Second Case: Tehran (Afsarie)-22 bus practical system (Falaghi et al., 2004)

Single line diagram of the system is shown in Fig. 4.

Fig. 4. Tehran (Afsarie) -22 bus practical system

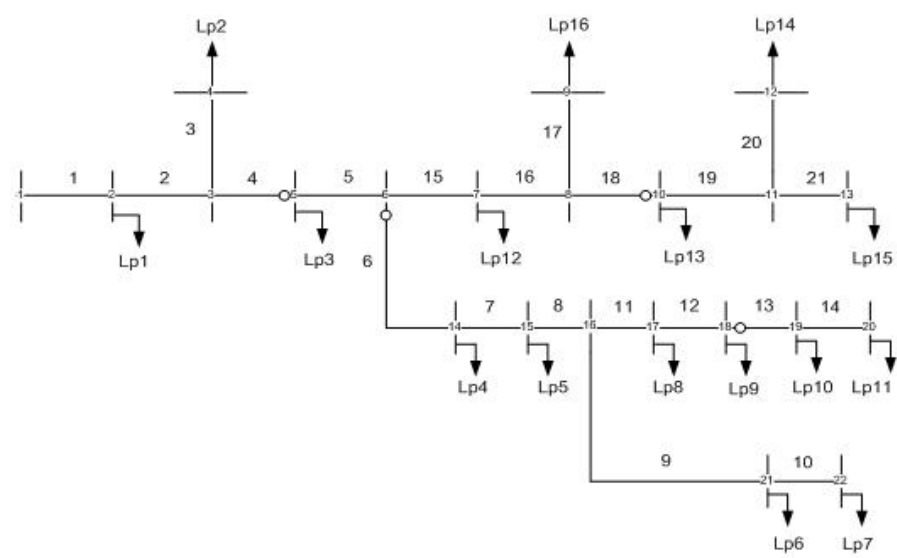

Research article

COIndian Society for Education and Environment (iSee)
"Improvement in DG \& customer reliability" http://www.indjst.org
Farhadi et al. Indian J.Sci.Technol. 
Table 2. DG Placement by various techniques for Tehran (Afsarie) -22 bus system

\begin{tabular}{|c|c|c|c|c|c|}
\hline \multirow{3}{*}{ Technique } & \multicolumn{2}{|c|}{ DG Installation } & \multirow{3}{*}{$\begin{array}{l}\text { Ploss } \\
\text { (kW) }\end{array}$} & \multirow{2}{*}{\multicolumn{2}{|c|}{ Bus Voltage (p.u. }} \\
\hline & \multirow{2}{*}{ @ bus } & \multirow{2}{*}{$\begin{array}{l}\text { Size } \\
\text { (MW) }\end{array}$} & & & \\
\hline & & & & Min. & Mean \\
\hline No DG & 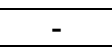 & - & 168.76 & 0.8869 & 0.9131 \\
\hline PSO & 13,18 & 1.25 & 50.00 & 0.9535 & 0.9625 \\
\hline DAPSO & 12,17 & 1.5 & 44.54 & 0.9632 & 0.9700 \\
\hline
\end{tabular}

Table 2 presents the results of the optimal sizes and locations of DG units. For multiple DG units, DAPSO achieves a loss reduction of $74.00 \%$ and $11.00 \%$ compared with no Dg and standard PSO, respectively. Also, bus voltage values increased significantly, for example DAPSO could raise the Mean value about 0.06 in per unit. About reliability, the values of EENS were 40000, 24983 and 18975 in $k W h / y r$ for no DG, PSO and DAPSO, respectively. The improvements were $52.56 \%$ and $24.04 \%$ with DAPSO in comparison to no DG and PSO.

\section{Conclusion}

In this paper, power loss and reliability analysis was performed using DAPSO method for multiple DG allocation. This method is improved and developed standard PSO for finding the size of different DG sizes and the best location for DG allocation. The number of DG units from the appropriate sizes and locations can reduce the losses to a considerable amount. Given the choice, DG(s) should be allocated to enjoy other benefits as well such as loss reduction. In this paper, impact of DGs sitting and sizing on power loss and reliability were evaluated. It was obtained that proper allocation could increase reliability of the customers even using the least DG sizes.

\section{References}

1. Acharya N, Mahat P and Mithulananthan N (2006) An analytical approach for $D G$ allocation in primary distribution network. Int. J. Elect. Power \& Energy Systems. 28(10), 669-678.

2. Ackermann $T$, Andersson $G$ and Soder $L$ (2001) Distributed generation: a definition. Electric. Power Sys. Res.57 (3), 195- 204.

3. AlHajri MF, AlRashidi MR and El-Hawary ME (2007) Hybrid particle swarm optimization approach for optimal distribution generation sizing and allocation in distribution systems. Proc. Canadian Confe. Electric \& Comp. Engg. Vancouver, Canada. pp. 1290-1293.

4. Atwa YM, El-Saadany EF, Salama MMA and Seethapathy R (2010) Optimal renewable resources mix for distribution system energy loss minimization. IEEE Trans. Power Sys. 25(1), 360-370.

5. Chung I, Liu W, Leng SM, Andrus DA, Cartes Steurer M and Schoder K (2009) Integration of a bi-directional DC-DC converter model intoa large-scale system simulation of a shipboard MVDC power system. Proc. IEEE ESTS, Apr. 2022, 318-325.

6. El-Khattam W, Hegazy YG and Salama MMA (2009) An integrated distributed with load models. IEEE Trans. Power Sys. 24(1), 427-436.
7. Falaghi $\mathrm{H}$ and Haghifam M (2004) Modeling and analyzing the impact of DGs on reliability of distributed generation. $19^{\text {th }}$ Conf. Proc. Int. Power Sys. Conf. (PSC), Tehran, Iran.

8. Gandomkar M, Vakilian M and Ehsan M (2005) A combination of genetic algorithm and simulated annealing for optimal distributed DG allocation in distributed networks. Proc. IEEE Electric. Comp. Engg. Can. Conf. 645-648.

9. Jen-Hao Teng (2003) A direct approach for distribution system load flow solutions. IEEE Trans. Power Delivery. 18 (3).

10. Kashem M, Ganapathy AV, Jasmon GB and Buhari MI (2000) A novel method for loss minimization in distribution networks. IEEE Int. Conf. Electric Utility Deregulation and Restructuring and Power Technologies.Proc.251-256.

11. Keane A and O'Malley M (2006) Optimal distributed generation plant mix with novel loss adjustment factors. IEEE Power Eng. Society General Meeting

12. Kennedy $J$ and Eberhart R (1995) Particle swarm optimization. Proc. IEEE Int. Conf. Neural Networks, Perth, Australia. 4, 1942-1948.

13. Marwali MN, Jung JW and Keyhani (2007) A stability analysis of load sharing control for distributed generation systems. IEEE Trans. Energy Conversion, 22(3), 737-745.

14. Navid Khalesi and Seyed Ali Mohammad Javadian (2011) Distribution system reliability with considering variation in DG and load consumption. Indian J.Sci.Technol. 4 (10), 1285-1289.

15. Ochoa LF, Padilha-Feltrin A and Harrison GP (2008) Evaluating distributed time-varying generation through a multiobjective index. IEEE Trans. Power Delivery. 23(2), 1132-1138.

16. Robinson J and Rahmat-Samii $Y$ (2004) Particle swarm optimization in electromagnetics. IEEE Trans. Antennas Propag. 52 (2), 397- 407.

17. Seyed Ali Mohammad Javadian and Maryam Massaeli (2011a)An adaptive overcurrent protection scheme for distribution networks including DG using distribution automation system and its implementation on a real distribution network. Indian J.Sci.Technol. 4 (11), pp: 14381445.

18. Seyed Ali Mohammad Javadian and Maryam Massaeli (2011b) A fault location method in distribution networks including DG. Indian J.Sci. Technol. 4 (11), 1446-1451.

19. Seyed Ali Mohammad Javadian and Maryam Massaeli (2011c) Calculation of maximum DG's capacity according to their location for remaining the protection coordination in distribution networks. Indian J.Sci.Technol. 4 (11), 1452 1457.

20. Singh D and Misra RK (2007) Effect of load models in distributed generation planning. IEEE Trans. Power Systems. 22 (4), 2204-2212.

21. Singh D and Verma KS (2009) Multiobjective optimization for DG planning with load models. IEEE. Trans. Power Systems. 24 (1), 427-436.

22. Thong VV, Driesen J and Belmans R (2007) Transmission system operation concerns with high penetration level of distributed generation. Proc. of Inter. Universities Power Engineering Conference, Brighton. pp. 867-871. 